\title{
RESISTENCIA EN TIEMPOS DE CRISIS. LA MIRADA CÓMPLICE (CONTAMINADA Y CONTAMINANTE) DEL INVESTIGADOR ${ }^{1}$
}

\author{
Román Reyes \\ Universidad Complutense de Madrid
}

Resumen: La mirada (la del investigador que mira), si asume su status de agente que se legitima en su oficio, si innova siendo responsable de la voluntad de progreso que hace explícita, supone: a) reafirmar la pretendida determinación histórico-social del conocimiento; b) admitir que la theoria (praxis) es una prótesis; y c) que es posible tocar sin con-tactar, trastocando.

Palabras clave: mirada cómplice, disculpas, pre-textos, complicidad, innovación

\section{Resistence in times of crisis. The complicit (contaminated and contaminating) gaze of the researcher}

Abstract: The gaze (that of the researcher that looks), if it assumes its status as an agent that legitimizes itself in its profession, if it innovates, while being responsible for the will to progress that it makes explicit, involves: a) reaffirming the alleged historical and social determination of knowledge; b) admitting that theoria (praxis) is a prosthesis; and c) that it is possible to touch without con-tacting, that is, trans-forming

Keywords: complicit gaze, apologies, pre-texts, complicity, innovation

El pensamiento es tarea de vagos y maleantes. Hay que saber perderse para trazar un mapa: vagar por los márgenes y por el desierto, fuera de las fortalezas en las que están encerrados la verdad, el bien y la belleza. Sólo los nómadas descubren otros mundos. Hay que saber pervertir la ley (jugar con ella) y a veces subvertirla (ponerla en cuestión) para cambiar y/o quitar la ley: provocar malos pensamientos en los bien-pensantes, asediar las sedes de la verdad, el bien y la belleza. Sólo los malditos mejoran este mundo. [Jesús Ibáñez. En: Román Reyes (ed), Michel Foucault, homenaje a un vago y maleante, Monográfico del periódico Liberación, № 6, Madrid, 30/12/1984]

SUMARIO: I Los textos como disculpas, pre-textos | II ¿Re-Pensar la Universidad?. Resistencia y sumisión | III Resistencia en tiempos de crisis | IV Biografía y Riesgo. Más allá de la Modernidad: a) Posiciones de partida; b) Biografías flexibles, de riesgo; c) Capitalismo flexible; d) Conclusión provisional 


\section{Los textos como disculpas, pre-textos}

La mirada (la del investigador que mira), si asume su status de agente que se legitima en su oficio, si innova siendo responsable de la voluntad de progreso que hace explícita, supone: a) reafirmar la pretendida determinación históricosocial del conocimiento; b) admitir que la theoria (praxis) es una prótesis; y c) que es posible tocar sin con-tactar, tras-tocando.

Se sabe/conoce lo que se incorpora a esa unidad compleja que es el cuerpo. Se sabe/conoce, en consecuencia, lo que se come y metaboliza. El desecho de lo engullido define lo que no se es o no puede uno llegar a ser.

Porque el discurso de/sobre lo real ya no es local, la mirada (lo que el investigador mira) supone a su vez: a) trans-nacionalizar / globalizar el pensamiento; pero b) sin perder la referencia del pensador, reforzando así las señas de identidad del origen.

Condicionar las propuestas teóricas a "modelos (académicamente) convencionales" es una temeridad. $O$, lo que es lo mismo, una irresponsabilidad: si lo real ya no es local, tampoco puede ser exclusivamente virtual. Y si la realidad es simbólica antes que mostrenca lo es en la medida que esa realidad pueda ser manipulada. Se manipulan las sombras, nunca los objetos que las proyectan. Conviene, por tanto, aprender a gestionar adecuadamente los enfoques.

Mi posición es, sin embargo, ambigua al respecto: yo invoco las manos. Tanto su uso in-mediato, su "voluntad de contacto" (tras-formando o re-creando), como su "voluntad de proyección más allá de su alcance in-mediato". En este sentido yo me considero un alevoso manipulador. Manipular es, en mi caso, 
humanizar. Controlo lo que es (estando cerca, al alcance de mis manos) para que sea "de otra manera".

Pero si se es responsable de la resistencia de las propias manos, la responsabilidad es subsidiaria si es débil o ineficaz (subjetiva y objetivamente) la resistencia de las prótesis que uno elija (compás, cincel o pincel, pluma 0 lápiz, cuerda ... palabra, discurso ...)

Sin embargo, habría que invocar (nuevamente) el origen: theoria es "mirar en profundidad": lo profundo no es sólo el sustrato (apuntalamiento) históricodiscursivo. Profundo (carencia de abismo o ab-Grund invertido) es sólo lo que da prioridad al sentido (geográfico y teleológico) de aquello de lo que hablamos. Localizar su posición sobre un plano, en un mapa (calcado o por definir). Y porque los mapas son proyecciones geométricas puede uno localizar (atrapar) lo otro, lo que transciende, en cualquier lugar o en ninguno, más allá incluso de mapa posible.

Se mira desde posiciones (cultural/socialmente) "cómplices". Mi mirada es siempre una "mirada constructiva". La ingenuidad (la dispersión) fue reprimida en su origen. Voluntad de sistema (plusvalía) vs voluntad de fragmento (minusvalía). El poder es siempre el que ejerce el poderoso "por derecho propio o delegado". No es emulable. Si quieres ser como dios, te expulsan del paraíso. Por no atreverte a ser competitivo. Por no aventurarte a convertirte en dios alternativo.

La "construcción" es la adecuación a un paradigma, un protocolo, que garantiza el reconocimiento del grupo de adscripción (la generalidad) cuestionando el de referencia (la singularidad).

Para descubrir "la huella de los clásicos" tiene uno que admitir antes conjuntos cerrados, un canon de referencia. Se incluyen a unos por exclusión de otros. Se incluyen a los "más pesados" (con legitimidad institucional) y se excluyen a los "livianos" (con escasa o nula legitimidad institucional). Los excluidos son necesarios, como los márgenes, porque son garantes, fundamento de la "integración" o "pertenencia" al canon.

El "interés" del momento convierte a los "clásicos" en a-temporales. Recuperables sólo desde el "interés" del posterior lector. A su vez, el que un "clásico" sea a-temporal le convierte en pre-texto o "legitimación" académicopolítica de cualquier programa o discurso. De ahí la paradoja (multiuso): la libre recurrencia y la no-credibilidad puntual de los "hagiógrafos" convierten un texto o a su autor en legitimadores de posiciones antagónicas.

Pero si se detectan huellas será recomendable desvelar su voz, apagada en el tiempo, recuperada en su eco. Sin duda, sería recomendable escuchar antes el "eco del silencio" que las bibliotecas guardan para vender "soledades". Es 
decir, para legitimar la firmeza de quien apuesta por la crítica, por el progreso en su sentido más literal. El riesgo que asume quien ha optado por "pensar por sí mismo". Por "cuestionar lo evidente".

Acusando el oído, nosotros "convenientemente ilustrados" y "legitimados" (ciudadanos "con papeles"), accedemos al "club privado del pensamiento noble". Se nos acredita. Se nos asigna un carnet que nos identifique como "miembro" para acceder a él. Si aceptamos las reglas de la "inclusión". Si "perdemos los papeles" nos perdemos a nosotros mismos, nos extra-viamos. Perdemos la referencia. Nos expulsan del club. Fuera nos esperan los encargados de "re-cluirnos" en bolsas de mejor identificación, de mayor control. Pero cualquier encierro es violable, porque existen los topos. O los resistentes. ¿De qué otra manera podría interpretarse la revuelta?.

¿Se acabó la era del sujeto?. Ahora somos pensadores "reconocibles" a través de una huella efímera: el papel que se nos asigna y tras el que nos reconocemos y nos hacemos reconocer. Pero la "legitimidad laica" es el enemigo interior "a desplazar". Para poder combatirlo si es imposible eliminarlo antes. ¿Por qué entonces nos empeñamos en fijar "objetividades"?. ¿Cómo puede entenderse un "acontecimiento autónomo", una "proposición firme", si quienes dan autonomía o fijan discursos son sólo los sujetos "acreditados" para "objetivar lo real", que, al hacerlo, "contaminan" sus propios productos?

El que en un "producto literario", estimativamente crítico, un autor no repare en que faltan (desde la perspectiva académicamente normada, legitimadora de status), "notas a pié de página" se explica porque el discurso de ese nocontaminado autor/pensador, joven por naturaleza (poco "ilustrado") o por vocación, no es posible sin haberse contaminado antes del discurso kantiano, hegeliano, marxista o frankfurtiano, por ejemplo.

Por la misma razón las Comisiones de Evaluación correspondientes deberían rechazar cualquier texto (con pretensiones de validez académica) por no citar a Aristóteles. La trans-versalidad del discurso (y su trans-ductividad) sólo es reconocible en nuestro medio cultural si se gesta sobre una lógica diádica, que, paradójicamente, es capaz de "incorporar" incluso las "variables cualitativas", que hacen "discursiva y ontológicamente visibles" hechos originariamente considerados "sólidos", definidos en su naturaleza y recurrente reconocimiento. Así podríamos entender a Walter Kaufmann o a Miguel de Unamuno cuando hablamos de "las máscaras de lo trágico".

Uno jamás y siempre estuvo al mismo tiempo en Hiroshima. El amor/pasión del investigador (¿o es que alguien es capaz de definir su oficio más allá de su particular pathos?) y las huellas de ese amor/pasión que su investigación registra, niega/cuestiona "lo evidente". Un deus ex machina sólo es in-vocable ante la impotencia o ignorancia del científico. En su caso, toda palabra es una palabra de más, ya que su discurso pertenece a otro orden. El discurso de lo 
real-concreto sólo se reconoce en el discurso de la resistencia. Jamás el discurso de la sumisión abre perspectiva alguna.

Porque resistir es vivir, sobrevivimos más allá de la palabra dicha, pronunciada. Mueren sólo los relatos. Los sujetos, sin embargo, permanecen para legitimar el cambio que esos relatos anuncian. Para ser testigos de "lo-todavía-noconscienciado". Para forzar el salto a "lo-todavía-no-acontecido". Las huellas de los clásicos se perpetúan, por tanto, en la huella intemporal que el investigador en ellos reconoce (como disculpa o pre-texto) para re-crear / re-pensar una historia por escribir, una revolución pendiente.

\section{¿Re-Pensar la Universidad?. Resistencia y sumisión}

Me considero un universitario, porque ustedes así me reconocen. Re-pensar, por tanto, la Universidad sólo me es posible si lo hago desde dentro: Qué sentido tiene hoy la institución (justificación histórico-social) y cuáles son sus expectativas de complicidad en el presente y futuro inmediatos. Para responder tendré que hablar (también) en primera persona. Porque ahora soy yo la voz de la universidad, que ustedes me prestan, al escucharme. Perdón, por tanto, por el metalenguaje.

Se supone que esto es un espacio para la transmisión crítica del pensamiento y un espacio, a su vez, para el diseño de formas nuevas de pensar ... para actuar en consecuencia. Se supone. Se nos dice que aquí se forman cuadros: Agentes normalizadores, que se ocupen de mantener un equilibrio inestablemente estable. "Al servicio de la sociedad", se nos recuerda también.

Jugando con pares de opuestos se insiste en la calidad: seremos excelentes si ofertamos una mejor producción. Mucho más excelentes aún (dimensión cuantitativa) si la rentabilidad se garantiza. Un feed-back sospechoso: Se vende estado de bienestar agudizando las desigualdades y concentrando los beneficios. Las pérdidas, se socializan.

Jugando igualmente con esos pares de opuestos-complementarios se nos ofrece aquí mejor formación para reforzar una mayor rentabilidad. Las 
prioridades se escalan según órdenes que responden antes a un interés para o extraacadémico.

La pretendida mayor movilidad que el EEES defiende es una trampa. Lo que se genera es mayor desencanto porque se crea una incierta bolsa de mano de obra. Disponible en función del mercado local, que valora y compensa la prestación cualificada. Pero la cualificación, en este supuesto, resulta ser un inestable valor aleatorio. Se invoca para justificar una elección, supuestamente racional.

Porque soy un provocador quiero dejar de ser un infractor anónimo. Por eso soy y seguiré siendo un resistente. Hablo y hablaré en público hasta que consigan liquidarme (profesional o físicamente). $\mathrm{Y}$ porque decir vecino es nombrar al competidor, al enemigo, he emigrado, dejando atrás la corrupta república del conocimiento. Sólo los nómadas mejoran este mundo. Los gestores de esta institución habrán de convivir con los topos. Ustedes deben dar testimonio de esa resistencia. Decir "no" es decir "sí" a lo-todavía-nonombrado, por nominar. Por eso no pongo nombres a las cosas. Para que las cosas no sigan siendo esclavas del discurso del poder. Ahora, tiempos de saturación, me importa más poner cosas a los nombres.

A lo largo de mi vida no me ha interesado aprender determinadas cosas. Por ejemplo, a decir basta. Porque soy un insatisfecho por vocación y por provocación. Porque quiero más o quiero de otra manera lo que tengo, lo que he conseguido. En un campo más flexible: allí donde no se sepa qué significa plenitud, saturación. Porque ahora (más allá de la modernidad) se completa de acuerdo con protocolos consensuados al margen de nuestro interés. Completar, es decir, cerrar ciclos o considerarlos agotados.

Lo otro es la imagen de la exclusión o del desecho. Se expulsa lo que no se puede digerir. Por voluntad propia o por incompatibilidad con las reglas del "consumo sano", las reglas de la integración a un cuerpo nunca acabado, siempre por definir / constituir.

"Ser la hostia" (un pensador "a-típico") es atreverse a desmitificar "lo sagrado" (lo de acceso restringido en "tiempos originales", asimismo recurrentemente invocados). Negarse a ser brutalmente apartado del soporte material que uno controla, negarse a ser catalogado como "alumno / bien élevé - suspendu ". Sois la hostia porque habéis permitido que vagos y maleantes como yo sigan minando el discurso académico-institucional.

Dios es el conjunto de lo que expulsamos. Dios, como venganza, usurpa lo que el hombre no puede soportar más: lo que produce, sin posibilidad siquiera de permanecer providente sobre su efímera obra. Los dioses, ociosos por 
definición, restan o niegan a su antojo liquidez. Se con-solida, por tanto, sólo lo que garantiza rentabilidad. Nos engañaron porque, al principio, se nos permitió pecar: un resbalón desdichado, ya que fuimos incapaces de (aprender a) pecar alevosamente.

Las estrategias modernas de dominación invocan el diálogo para integrar la contestación, la disidencia. No caigan en la trampa: la Universidad son ustedes. Si no son ustedes quienes la ocupen, desaparece. Se les seduce para que la ocupación sea tutelada. Pero por los pasillos de Facultades e Institutos no circula ya el pensamiento. O circula clandestinamente. Prevalece tan sólo la sombra huidiza de un discurso anclado en el tiempo. Estructuras panópticas, centros de reclusión en régimen simbólicamente abierto. En eso se han convertido las Universidades.

Bolonia (EEES) representa lo más insolidario de la Vieja Europa. Bolonia no resuelve el problema. Lo reconvierte, simulando modernidad. O lo que es lo mismo, institucionalizando sospechosos mecanismos con aparente voluntad de "compensación intercomunitaria", de competitiva distribución democrática. Bolonia ha sentado, sin embargo, las bases jurídico-sociales para la privatización de la gestión del conocimiento.

Quien advierte no es traidor. Reparen en lo obvio: Ustedes son (pueden ser) los neófitos / novicias, presas fáciles de acosadores o pederastas del sistema.

Porque guardar silencio es un acto de rebeldía les devuelvo la palabra, que ustedes tuvieron a bien prestarme. Un respetuoso beso. Porque ahora no es tiempo de orgasmos.

\section{III}

\section{Resistencia en tiempos de crisis}

Cuando la resistencia se convierte en obligado estilo de vida es posible que estemos llegando a un punto de no-retorno.

La resistencia pasiva es una forma de sumisión encubierta. 
La resistencia activa puede tener dos grados 0 niveles de visibilidad: Resistencia discursiva o resistencia militante.

La resistencia discursiva describe y denuncia. Pero el discurso resistente termina por ser catalogado como "provocación" innecesaria, e incómoda. Inoportuna, por tanto, para reforzar estrategias de lucha que pueda suscribir formación política alguna.

La resistencia discursiva circula por canales transgresores (aunque tolerados). La legitimación es marginal, no por ello menos visible. Al discurso sobre la resistencia tienen acceso los (presuntos) infractores. Aunque a sus textos se aproximen "investigadores independientes" con ánimo de catalogar "rarezas" (más o menos irrelevantes), "anécdotas efímeras", en todo caso.

El silencio resistente es la antesala de la revuelta. $\mathrm{O}$ el motor que la activa.

La resistencia militante se apuntala en la resistencia discursiva. Genera así nuevas posiciones teóricas, que obligan a repensar el discurso resistente originario.

La acción es un complemento del silencio cómplice. Socialmente "patológico". Porque actuar es asediar sedes: de la razón, en un primer momento, como trampolín para ocupar el poder.

Hablar como estoy hablando, en tiempos de crisis, pudiera ser considerado reaccionario. Porque no sabemos si lo que realmente nos mueve, los objetivos que perseguimos, es tan sólo un cambio de protagonismos o, por el contrario, de sistema.

No lo sabemos porque, a pesar de Nietzsche, todo sistema sigue siendo un sistema de más. Porque cualquier sistema terminará (a menudo, sin pretenderlo) identificándose con la voz del jefe. $Y$ si ese jefe se convierte en absoluto su palabra es "la" realidad. Jamás proyecto o invitación para transformar el mundo.

No hay revuelta, a mi modo de entender, si no devaluamos antes, si no neutralizamos, las estructuras de poder tradicionales. $Y$ las relaciones (negativamente resistentes) de la ciudadanía con esas estructuras de poder.

Hablar de resistencia es hablar de responsabilidad. El discurso de la acción se legitima como discurso resistente si el imparto en las conductas y en la organización es evidente. 
La opinión pública no es opinable. Uno piensa un pensamiento "que circula", normado. O esa opinión carece de valor. Los procesos de valoración son, por ello, procesos de reclusión. Discurrir es transitar, correr, desplazarse por conductos impermeables, sobre plataformas finitas que garantizan la solidez del soporte.

Cuando alguien "se reserva su" opinión está simulando: simula que obedece o, simplemente, "opina" para confundir, simulando sumisión.

Un des-carriado es, por eso, un mal-pensante.

Un único orden del discurso. O el orden que el discurso (del poder) instaura y perpetúa.

La crisis es un descriptor-trampa. Es un recurso institucionalmente registrado para ocultar lo obvio: la inversión de valores y el despilfarro de recursos.

La crisis es un descriptor per-verso. Cuando se invoca como pre-texto se nos niega la re-visión de lecturas y se nos impone una con-versión de valores no rentable.

La crisis es un descriptor trans-vertido. Se utilizan los media para llamar subversión a cualquier estrategia de defensa que suponga repliegue o nocolaboración. Se nos llama intro-vertidos cuando denunciamos la brutal revisión a la que se somete una escala de valores mínimamente sostenible.

Se nos hace creer que vamos hacia alguna parte diferente, cuando se nos niegan recursos y se nos roban los medios para ponernos en camino.

La simulación de movilidad es crueldad: hacer creer que estamos camino de "otra parte" cuando ni siquiera se nos permite abandonar el punto de partida, ni verificar si esa "otra parte" existe. Cuando se nos tiene atrapados en el punto de salida.

Volvemos al origen, al punto (supuestamente) de partida para recrear nuevamente caminos (pretendidamente) recorridos. Pero, en esta ocasión estando atentos a los detalles ... las trampas que nos han tendido y los mecanismos de superación que se nos ha permitido activar.

El trauma, la caída, nunca, jamás tiene un origen metahumano.

Si bien el posterior diagnóstico puede ser fácil, no es tan fácil diseñar terapias que nos permitan recuperar el tiempo robado para invertirlo en tiempo por 
consumir, sin providencia de naturaleza alguna. La tragedia tiene un nombre: los amores (como el riesgo de asumir un compromiso) han de seguir siendo secretos para que alguien pueda identificarnos como amantes.

Terminamos llamando "cobardía" a la prudencia. Coherencia, al alago. Reconciliación, al olvido. Generosidad, a la impotencia o la inhibición

\title{
Biografía y Riesgo. Más allá de la Modernidad
}

\begin{abstract}
Quien se aventura a abrir otras ventanas, por donde entren y salgan otros vientos, está condenado a perderse en ese vértigo .. a caer, deslizándose hacia un vacío que jamás va a tocar fondo. Pero sólo los aventureros saben del abismo, conocen el riesgo. Sólo ellos diseñan caminos otros que facilitan la huida ... hacia lo otro. Sólo los mal-ditos pueden ser genuinos creyentes. [Román Reyes, Graffitti, 13]
\end{abstract}

\section{1) Posiciones de partida}

a) Consecuencias sobre el "individuo", soporte de la "persona". En un mundo saturado de información se reducen las posibilidades de discriminar, de "elegir". Ya no nos sirve el discurso tradicional sobre la vida cotidiana. La cotidianidad ahora es mucho más compleja. La complejidad, sin embargo, puede ser garante de integridad. Aunque reste autonomía. En la medida que "lo propio" se ha convertido en la metáfora de "lo común".

b) El cuerpo reproduce la imagen. Nuestros cuerpos son perceptibles si previamente han sido homologados como objetos refractantes. Porque emulan al emisor, a las fuentes, ampliando y prolongando (cuando no traduciendo) el efecto de sus mensajes. La sacralidad del cuerpo se ha prostituido. Sacralidad o misterio que, tal vez, se protege con un uso "clandestino" de las manos. Decir, por tanto, cuerpo es hablar de producto de "consumo público". Abandonar el espacio doméstico se ha convertido en una trágica metáfora: de casa al burdel y del burdel obligadamente de vuelta a casa.

c) Pre-definir o pre-decir un ciclo ya no es fiable. ¿Se acabó la era de la anticipación?. ¿Desapareció, por tanto, la fruición o anticipación ritual del placer?. ¿Se ha apagado, en consecuencia, el motor primero del cambio, la 
esperanza?. Ahora es la "sorpresa", la "imprevisión" quien determina el "tempus" (la oportunidad), la "natura" (la legitimidad) y el "sentido" (la eficacia) de los ciclos. Mañana es una pasión inútil. Sin pathos, repito, no hay estímulo. Quedamos a merced de "lo indecible", lo "inenarrable". Otra definición de "lo sublime", que, sin embargo, no se identifica como carencia o deseo.

d) El "novum" sorprende sólo como circunstancia. El acontecimiento de su llegada es lo único que "asombra" y que, por tanto, marca, permanece. No hay acumulación que el sujeto controle. Se registran formas, figuras. Tal vez, sensaciones. El sujeto se ve obligado a "re-orientarse" respecto a los objetos o acontecimientos nuevos, instalados en el entorno personal más cercano. Se refuerza así una sociología del instante, sin voluntad siquiera de permanencia. "Después" es tan sólo el descriptor de un deseo impronunciable, de una "voluntad sin ilusión". Se refuerza lo inmediato, lo provisionalmente propio. Se recupera a un individuo "sin atributos", cuestionando la constitución histórica del entorno que le determina y del conjunto de selectivas técnicas que protegían su "identidad", estrategias efímeras de "diferencia": los sitios que se habían ocupado (platzbesitzer) y las posiciones que se habían conquistado (platzhalter).

\section{2) Biografías flexibles, de riesgo}

a) Describir es la fase previa. Los fundamentos de/para un posterior relato: historia de vida. Describimos lo que vemos (o creemos haber visto) y lo que la memoria selectivamente ha acumulado. La literatura cierra ciclos. Para posibilitar la apertura de otros nuevos (recuperando incluso ciclos previamente cerrados).

b) Toda bio-grafía implica riesgo, salvo que sean restrictivas, que cuenten tan sólo lo "visible para todos", la imagen generalizada para consumo de competidores. Porque sólo se conoce lo que se "engulle". Por eso todo lector es un depredador en potencia. Leer es conocer (o pretender conocer) el soporte del discurso manifiesto. "El hijo es lo mismo que el padre", precisamente porque le ha matado. ¿Edipo vs Tántalo?.

c) El escritor arriesga lo más íntimo de su privacidad. Especialmente si sus lectores pueden "deconstruirle". La cercanía, proximidad o similitud de historias de vida es un riesgo que el escritor asume. Aquello que las palabras ocultan puede quedar, entonces, de manifiesto.

d) Aunque uno expulse (para aniquilarlo) al "enemigo que lleva dentro", y precisamente por eso, toda bio-grafía es también auto-destrucción. Eu-thanasia simbólica. El escritor se convierte en hagió-grafo de su historia: "organiza" los pre-textos para vender un texto "coherente". Es, a la vez, acusador, instructor, juez y verdugo de sí mismo. La auto-imputación es un táctica peligrosa. Toda bio-grafía será, por tanto, incompleta. Porque quien la escribe no ha cerrado aún su ciclo vital. Las estrategias para preservar su integridad no siempre son eficaces. En un mundo desigual, y en el que se refuerzan las desigualdades, la 
personalidad del autor y del lector es esquizoide: la respuesta es desigual (contradictoria, a veces) en función de la específica reacción del sujeto ante ataques obligadamente dispares, interesados. Decir lo que se puede escuchar y escuchar lo que se espera oir. Ésa es la cuestión. ¿Una cuestión semántica porque el asesinato es un suicidio con mala puntería? (Norman Brown)

\title{
3) Capitalismo flexible
}

\begin{abstract}
Los conceptos "verdadero" y "falso" forman parte de un lenguaje propio de un mundo muy específico. En las investigaciones de este tipo, en cambio, no se trata tanto de producir verdades cuanto de conseguir un entendimiento, una comprensión que constituye también conocimiento objetivo, aunque de un tipo muy peculiar, que permite descubrir qué es lo que hace que otro ser humano sea diferente de uno mismo. [Richard Sennett]
\end{abstract}

a) Permanecer atado, dependiente de un discurso académico-político que "justifica" y "prescribe" antes que "critica", que "explica" lo que es desde una perspectiva "normada", supone anteponer el orden del discurso (sedentarismo) al orden de lo real en proceso de constitución (nomadismo). Frustrar (reconvirtiéndolos) el deseo y la voluntad de cambio, más allá de una modernidad trascendida.

b) Es obvio que, aunque con resistencia, los intelectuales admitan hoy en día que "cohesión" y "competitividad" son conceptos que no pueden ir de la mano. Ése es el problema, que no terminamos de plantear "correctamente". Por esta razón, en el capitalismo, al menos en su etapa actual, no puede haber conciliación entre las ganancias económicas y la cohesión social. Este capitalismo de nuevo cuño demanda responsabilidad: que cada cual asuma en solitario el riesgo de enfrentarse al destino. No hay lugar, bajo este supuesto, a una responsabilidad colectiva, solidaria

c) Sobrevivir en reales "tiempos de penuria" es imposible sin una cierta "disciplina", simbólica y necesaria fuerza psicológica para situarse frente a la desigualdad y la injusticia. La fortaleza se impone, una personalidad resistente frente a un cada vez más agresivo sistema capitalista que destruye al individuo tanto en el plano social como a nivel psicológico. Ni siquiera el capitalismo clásico era tan demoledor. Ante la impotencia que el neo-capitalismo genera, una reconstrucción de la propia personalidad requiere un nuevo diseño de las estrategias de lucha, formas de efectiva oposición hasta ahora no catalogadas.

d) La debilidad e inestabilidad de las redes nos obliga a buscar soportes/seguridad hacia y desde dentro. Mi seguridad ya no es un reflejo o un duplicado micro de los modelos de producción macro (económico-político y religioso-afectivo). Es, tal vez, tiempo de redefinir la política. Los sistemas de representación y gestión de lo público. Como es también necesario redefinir el sentido de la participación y responsabilidad en esa gestión. Porque lo privado es ahora más que nunca inestable, débil. Por más que finjamos resistir 
asumiendo las consecuencias de una disidencia de difícil, cuando no incierta, organización.

\section{4) Conclusión provisional}

"Cuando me dijeron libertad ya era demasiado tarde. | Había perdido la referencia, | había perdido el habla, | había agotado los filtros: | el discurso de la reconversión | --mi viejo discurso de la seducción y de la provocación-- | había empezado a serme extraño. || Llegaron demasiado tarde los dueños del teatro, | los guardianes de los textos, | los administradores de lecturas. I| ¿Cómo voy a pronunciar --a partir de ahora-- | palabras-proyecto, palabrasmensaje ... | palabras-denuncia?. || ¿Cómo ocultar entonces mi impotencia, | cómo escribir paz, respeto, dignidad ... | sin que me tiemblen las manos?. I| Ellos, los gestores de la integridad, | han prostituido el discurso de la vida. || Ellos, que no entienden de contenidos | más allá de la ficción | que su interés genera e imponen. || Cuando me dijeron libertad habían hecho de mí | un recluso de por vida. || ¿Cómo voy ahora a organizar mi resistencia, | cómo mi estrategia, cómo mi compromiso, | si cuando grite libertad nadie emprenderá cerca | vuelo autónomo alguno?. || Porque llegaron a su tiempo, | Cuando me dijeron libertad | ya era demasiado tarde" [Román Reyes, Los papeles del silencio]

\footnotetext{
${ }^{1}$ Recopilación de esquemas reelaborados, soportes de las intervenciones que el autor tuvo en la Università de Salento, en la Oficina Cultural ERGOT y en el Espacio Social ZEI, Lecce-Italia, Junio y Noviembre.2011
} 